\title{
Searching for underlying social determinants of health for thirty-day hospital readmissions
}

\author{
Matthew Wilson, Kathleen Savoy, Jeff Dubin, Edward Floyd, Matthew Paik, Ira Rabin, Dave Milzman \\ Medstar Washington Hospital Center, Washington, DC, United States
}

Received: August 12, 2019

Accepted: October 8, 2019

Online Published: October 12, 2019

DOI: $10.5430 /$ jha.v8n6p24

URL: https://doi.org/10.5430/jha.v8n6p24

\begin{abstract}
Objective: An evaluation of social factors associated with 30-day readmission was undertaken at our institution to determine which factors would be significantly associated with time to hospital readmission.

Methods: Prospective observational study at an academic tertiary care hospital in the mid-Atlantic region of patients who were readmitted within 30 days of their last inpatient discharge. The electronic health record in conjunction with the regional hospital information system was used to generate a daily report to identify a convenience sample of readmitted patients. Using a standardized interview, data on 117 patients were collected for an exploratory analysis of social factors associated with readmission.

Results: Regression modeling demonstrated poor correlation with prediction of time to readmission $(\mathrm{R}$-squared $=0.2189)$. No individual social variables were found to be significant for influencing time to readmission (all $p$-values $>.05$ ). Common social factors were seen within the population affecting their utilization and access of healthcare. Poly-pharmacy was found in the majority of patients. Self-reported medication adherence was good, except with regards to mental health medication compliance. 97\% of patients reported filling their prescriptions. 36\% of the patients went to their follow-up appointment within 7 days although the vast majority of patients (92\%) reported having a primary care doctor. $23 \%$ of patients expressed difficulty getting to their follow up appointments.

Conclusions: At one single-center tertiary care hospital, there were some common underlying social determinants of health that may be related to readmission; however, no factors in isolation were predictive of hospital readmission. While there are common themes among readmitted populations, particularly in regard to factors driven by poverty, it is likely that the complex interaction of social factors with health continues to limit attempted administrative modeling of these data.
\end{abstract}

Key Words: Thirty-day readmission, social factors, discharge planning

\section{INTRODUCTION}

Hospital readmissions are costly; ${ }^{[1]}$ frequently are deemed preventable; and noted to be a negative quality marker of inpatient care. There is wide variability in readmission rates with some hospitals having excess readmission ratios in many Centers for Medicare and Medicaid Services (CMS) categories. ${ }^{[2]}$ Understanding why certain patients are more likely to be readmitted to the hospital based on the various social determinants of health may be beneficial ${ }^{[3]}$ in developing care pathways related to reducing hospital readmissions based on social factors. Current predictive models for hospital readmission correlate poorly with future readmission risk; have inconsistent performance; and have focused on general medical condition related variables. ${ }^{[4]}$ Very few prior models

${ }^{*}$ Correspondence: Matthew Wilson; Email: mdw12@medstar.net; Address: Medstar Washington Hospital Center, 110 Irving St. NW, Washington, DC, 20008, United States. 
have focused on social predictors of health such as income, employment, education, insurance status, caregivers, home health and access to care. ${ }^{[5]}$

An evaluation of social factors associated with 30-day readmission was undertaken at our institution. The goal of the project was to understand which patients are more likely to be readmitted to the hospital based on demographics and contributing social risk factors using face-to-face interviews; hypothesizing that from a pre-determined list of social determinants of health, one or more of these risk factors would be significantly associated with time to hospital readmission.

\section{Methods}

Prospective observational study at a 926 bed academic tertiary care hospital in the mid-Atlantic region of patients who were readmitted within 30 days of their last inpatient discharge. Patients were excluded from analysis if they were under the age of 18; planned readmissions; admitted to a psychiatric, labor and delivery or managed care unit; or nonEnglish speaking. After obtaining IRB approval, the electronic health record (Microsoft Amalga, Redmond, Washington) was used in conjunction with the Chesepeake Regional Information system for our Patients (CRISP) to generate a daily report identifying a convenience sample of patients who had been readmitted within 30 days. Using a standardized interview tool, trained medical students interviewed 117 patients and entered data into an electronic database (Microsoft Access, Redmond, Washington). Table 1 demonstrates a summary of the questions from the comprehensive interview questionnaire shortened for brevity. This tool was derived internally and reviewed by hospital administration before standardization of the script occurred to facilitate training of the medical student interview team in order to ensure consistency. The primary outcome of the study was defined a priori as an exploratory analysis of social factors associated with admission. Given the hypothesis generating nature of the study, alpha was set to 0.05 and was not adjusted for multiple comparisons. Stata (Version 14; StataCorp LP, College Station, Texas) statistical software was used to generate multivariate regression models evaluating time to readmission (total number of days from discharge to readmission) in the 96 patients that contained responses to all categorical variables presented in Table 1 as well as the continuous variable "age". A descriptive analysis of socio-demographic variables was also undertaken to provide an understanding of hospital wide readmission patterns.

\section{RESUltS}

Regression modeling demonstrated poor correlation with prediction of time to readmission $(R$-squared $=0.2189)$. None of the individual variables presented in Table 1 were found to be significant for influencing time to readmission (all $p$-values $>$.05). The median age of patients was found to be 58.1 (std dev 14.6) with $43 \%$ of the patients greater than 65 years old. Table 1 presents socio-demographic factors identified from the survey. Notably, $74 \%$ of patients were African-American consistent with the hospital's predominant population served. $65 \%$ of the patients interviewed had received education at or below the level of a high school diploma or GED. 78\% of patients were from neighborhoods with a median household income of $\$ 39,000$ or less.

Table 1. Shortened version of survey questions for social factors affecting readmission, $p$-values presented are from multivariate linear regression modeling of time to readmission (days from discharge to readmit)

\begin{tabular}{|c|c|c|}
\hline Survey Question & $\begin{array}{l}\text { Proportion } \\
\text { Responding "Yes" }\end{array}$ & $p$-value \\
\hline Unemployed & 0.10 & .331 \\
\hline Disabled & 0.11 & .578 \\
\hline African-American & 0.74 & .367 \\
\hline Male & 0.51 & .258 \\
\hline Saw PMD within 7 days & 0.36 & .174 \\
\hline Current smoker & 0.12 & .511 \\
\hline Past smoker & 0.50 & .451 \\
\hline Current alcohol use & 0.26 & .600 \\
\hline Past alcohol use & 0.66 & .591 \\
\hline Current illicit substance use & 0.04 & .788 \\
\hline Past illicit substance use & 0.28 & .244 \\
\hline Treated for substance abuse & 0.09 & .079 \\
\hline $\begin{array}{l}\text { Taking mental health medications as } \\
\text { prescribed }\end{array}$ & 0.28 & .940 \\
\hline Mental health diagnosis & 0.21 & .193 \\
\hline Mental health treatment & 0.18 & .144 \\
\hline GED or Highschool completion & 0.76 & .335 \\
\hline College Completion & 0.35 & .173 \\
\hline Graduate School Completion & 0.12 & .202 \\
\hline Problems with Discharge Instructions & 0.13 & .808 \\
\hline Discharged with Medications & 0.73 & .460 \\
\hline Able to fill prescriptions & 0.97 & .244 \\
\hline Took medications as prescribed & 0.91 & .080 \\
\hline Has help for medication assistance & 0.40 & .912 \\
\hline Lives with someone & 0.85 & .510 \\
\hline Home health aide at home & 0.18 & .067 \\
\hline Personal care aide at home & 0.09 & .190 \\
\hline Follows diet & 0.49 & .253 \\
\hline $\begin{array}{l}\text { Has difficulty getting to } \\
\text { appointments }\end{array}$ & 0.23 & .981 \\
\hline Has primary care physician & 0.92 & .696 \\
\hline Follow up scheduled at discharge & 0.71 & .440 \\
\hline
\end{tabular}


Common social factors were seen within the population affecting their utilization and access of healthcare. Polypharmacy was found in the majority of patients with $31 \%$ of patients taking 3-5 medications, $41 \%$ taking 6-10 and $23 \%$ taking 10 or more medications. Self-reported medication adherence was good (91\%), except with regards to mental health medication compliance (28\%). Impressively, $97 \%$ of patients reported filling their prescriptions, possibly helped by the $73 \%$ of patients that had their prescription dispensed at discharge (bedside dispensing). Only $36 \%$ of the patients went to their follow-up appointment within 7 days despite that the vast majority of patients $(92 \%)$ reported having a primary care doctor. $23 \%$ of patients expressed difficulty getting to their follow up appointments.

\section{Discussion}

In the patient population served by this hospital, there were some common underlying social determinants of health that may be related to their readmission to the hospital; however, no factors in isolation were predictive of hospital readmission. Limited prior attempts to model social factors affecting readmission have also been poorly predictive and our findings are similar. ${ }^{[6]}$ While there are common themes among readmitted populations, particularly in regard to factors driven by poverty, ${ }^{[7]}$ it is likely that the complex interaction of social factors with health continues to limit attempted modeling reflecting the underlying challenges in administrative utilization of these data. In particular, recurring themes included poly-pharmacy, non-attendance of follow up and inadequate transportation.

Limitations of the study include its small patient population, single center design, and that interviews were limited to En- glish speaking patients on the general medical/surgical floors. These exclusions were felt necessary at an adult hospital with access limitations in place on some wards and lack of research team access to prolonged interpreter resources.

Many survey questions centered on patient's ability to obtain follow up and medications after discharge. Most patients had a primary care doctor (92\%) and had scheduled follow up or specialist care already on discharge. It is possible that the increasing attention provided to factors affecting health care access at discharge is already adequately compensating for underlying social risk factors for readmission that were resultantly not uncovered in this model (type II error). Overall medication compliance was good (91\%) which was likely helped by the large proportion of bedside dispensing. The importance of anticipatory outpatient medication management has also been previously demonstrated prospectively by randomizing patients to intensive pharmacist interventions prior to discharge. ${ }^{[8]}$ Future studies are needed to determine whether a continued focus on preventing 30-day readmission can uncover usable predictive interactions for clinical workflow.

\section{ACKNOWLEDGEMENTS}

The authors would like to thank the following scholars for their support to this study: Daniel Toscano, MS, Colleen Hamm, MS, Hepzibha Alexander, RN, Douglass Johnson, MS, Khaled Kabbara, MS, Robert Hagerty, MS, Arsha Ostowari, MS, Alexander Oster, MS, Christopher Kyaw, MS, Andrew Horn, MS, Aidan Neustadtl,Brandon Passano, MS.

\section{Conflicts of InTERest Disclosure}

The authors declare they have no conflicts of interest.

\section{REFERENCES}

[1] Jencks SF, Williams MV, Coleman EA. Rehospitalizations among patients in the medicare fee-for-service program. N Engl J Med. 2009; 360:1418-1428.

[2] Readmissions Reduction Program (HRRP) - Centers for Medicare \& Medicaid Services. 2016. Available from: https://www.cms . gov/medicare/medicare-fee-for-service-payment/acu teinpatientpps/readmissions-reduction-program.html. Accessed 31 August 2016.

[3] Sills MR, Hall M, Colvin JD, et al. Association of Social Determinants With Children's Hospitals' Preventable Readmissions Performance. JAMA Pediatr. 2016; 170: 350-358.

[4] Zhou H, Della PR, Roberts P, et al. Utility of models to predict 28-day or 30-day unplanned hospital readmissions: an updated systematic review. BMJ Open. 2016; 6: e011060. https ://doi : 10.1136/bmjopen-2016-011060

[5] Kansagara D, Englander H, Salanitro A, et al. Risk prediction models for hospital readmission: a systematic review. JAMA. 2011; 306(15): 1688-98.

[6] Richmond DM. Socioeconomic predictors of 30-day hospital readmission of elderly patients with initial discharge destination of home health care. University of Alabama at Birmingham. 2013.

[7] Joynt KE, Jha AK. Thirty-day readmissions - truth and consequences. N Engl J Med. 2012; 366: 1366-9.

[8] Ravn-Nielsen LV, Duckert M, Lund ML, et al. Effect of an inhospital multifaceted clinical pharmacist intervention on the risk of readmission. JAMA Intern Med. 2018 Jan 29. https ://doi : 10.1001/jamainternmed.2017.8274. [Epub ahead of print] 